\title{
KINETICS OF PRODUCT SYNTHESIS IN CONTINUOUS ALCOHOLIC FERMENTATION
}

\author{
V. L. Yarovenko and B. M. NAKHMANOVICH \\ All-Union Research Institute of Fermentation Products, Moscow, USSR
}

\begin{abstract}
Laboratory and plant experiments were carried out on the continuous production of ethyl alcohol using starchy materials converted to hexoses by externally-formed enzymes. First order reaction kinetics was found to be adequate for the description of the process of ethanol synthesis by Saccharomyces cerevisiae.
\end{abstract}

\section{INTRODUCTION}

The growth of microorganisms and their biological activity under conditions of continuous cultivation are ruled by certain laws described in numerous papers ${ }^{1-10}$. Continuous alcoholic fermentation of starchy materials must be carried out as a multistage homogeneous process because of the necessity of complete utilization of carbohydrates fermented by Saccharomyces cerevisiae due to the high initial substrate concentration, viz. 15 to $17^{\circ} \mathrm{B}$.

During fermentation the starch is converted by the malt and mould enzymes; therefore the fermentation of carbohydrates in starchy media, and thus the formation of alcohol, depends on the activity of the saccharifying enzymes.

When choosing the number of stages it is necessary to take account of the principles of liquid movement in a series of vessels and of the conditions of maintaining the medium aseptic ${ }^{8}$. The fermentation line consists of 10 to 12 fermenters in series. In order to exclude the effect of wort retention on the growth of the contaminating microorganisms under commercial conditions a compulsory successive emptying of the vessels and their preventive sterilization should be periodically used ${ }^{11}$.

Fundamentals of product formation under continuous cultivation of microorganisms have been described by $\mathrm{Fencl}^{7}$. Differences between individual stages of the biomass and product formation follow from an examination of the growth curve. Depending on the type of the product, its formation rate may in some cases be directly proportional to the growth rate but Fencl has failed to find a strict dependence in others. The object of this work was to study the dynamics of continuous alcoholic fermentation of wheat mashes 
in laboratory size apparatus as well as under plant-scale conditions at the Michurinsk experimental plant.

The laboratory series of vessels consisted of 10 successive cylindrical vessels made of organic glass having a contents two litres each. It was equipped for electrically-measured dosing and mounted in a thermostatic room specially designed for this purpose.

On the plant scale the continuous method of fermentation was practised ${ }^{8,9}$. The quantity of the yeast transferred from a large-scale inoculum tank into the first fermenter is about 30 per cent of its volume. The saccharified mash was also pumped into the first fermenter.

\section{THEORETICAL}

Relations between biomass and product formation have been studied in continuous fermentations and the specific rate of alcohol formation in individual fermenters at different fermentation times has been calculated.

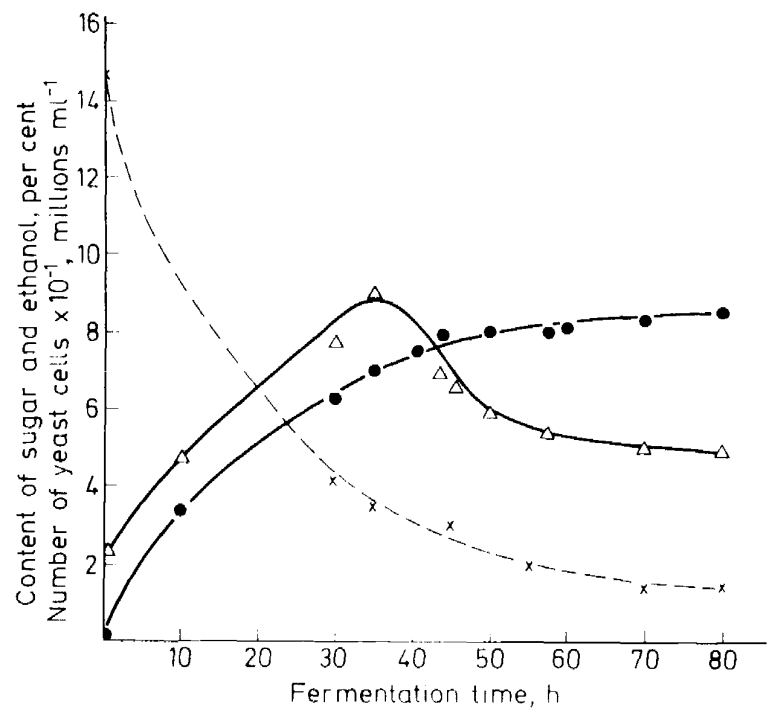

Figure 1. Fermentation dynamics of continuous alcohol fermentation. $\Delta$-- yeast number: -ethanol content : $\times$ sugar content.

Figure 1 shows the fermentation dynamics in one of the production cycles with malt-converted wheat mashes (as is still done in the majority of alcoholproducing enterprises); each point on the ordinate axis equals 10 million yeast cells in one millilitre. Periods of filling up of individual fermenters are quite different, the short ones resulting from the use of wort pumps.

The curves representing alcohol formation and yeast amount were nearly parallel up to 35 hours of fermentation. Then the growth curve gradually decreased (from 87.5 to 57.0 millions of cells per millilitre), while the alcohol accumulation continued to increase. The yeast partially lysed. In other 
production tests the growth rate maximum was higher (100 million or more per millilitre) but the character of the growth and alcohol-formation curves was similar.

Alcohol was formed in continuous fermentation according to logarithmic curves and its synthesis could be described by a first order reaction rather than a zero order one as is considered to be the case for many fermentation products ${ }^{7}$.

Continuous discharging of the vessels in series by pumping out the final wort was done during various tests for 5 to 56 hours. The number of yeast cells in the vessels of the series was small, mostly 35 to 50 million per millilitre, but it was sufficient for adequate fermentation of carbohydrates in the medium to form ethyl alcohol. The starch in those tests was converted by using an Asp.batatae culture.

The specific rate of alcohol formation $K$ was calculated for different ferementers and for different fermentation times. $K$ is actually the amount of the product in millilitres produced by one gram of biomass in an hour. Thus, for a two-stage cultivation, when the product is formed in the first and second stages, the process kinetics may be expressed ${ }^{7}$ by the balance relation

$$
\underset{\text { inflow }}{D_{2} P_{1}}+\underset{\substack{\text { product } \\ \text { formation }}}{K_{2} X_{2}}-\underset{\text { discharge }}{D_{2} P_{2}}=\frac{\mathrm{d} p}{\mathrm{~d} t}
$$

It is easy to show for a given state when $\mathrm{d} p / \mathrm{d} t=0$ and for similar dilution rates $D$ (the medium was pumped at an equal rate to the first fermenter only)

$$
\begin{aligned}
& K_{1}=\frac{D P_{1}}{X_{1}} \\
& K_{2}=\frac{D\left(P_{2}-P_{1}\right)}{X_{2}} \\
& K_{3}=\frac{D\left(P_{3}-P_{2}\right)}{X_{3}}
\end{aligned}
$$

etc., where $K_{1}, K_{2}, K_{3}$ represent the specific rate of alcohol formation in the first, second, third etc. fermenter in millilitres per litre, respectively, and $X_{1}, X_{2}, X_{3}$ are concentrations of yeast biomass in corresponding fermenters in grams per litre. According to some work ${ }^{12}, 10^{9}$ yeast cells weigh approximately 70 milligrams, or conversely each 10 million cells weigh about 0.7 milligrams. Thus one gram of yeast biomass in one litre or $1 \mathrm{mg} \mathrm{ml}^{-1}$ corresponds to 14.3 million cells in one millilitre. This proportion was used to establish the amount of biomass based on the number of cells.

Table 1 and Figure 2 show the calculation results for the specific rate of alcohol formation in one of the experiments. The $K$ values were highest in the first fermenter (1.76-2.73) while in the following fermentation stages they became considerably lower, decreasing by a factor of 2.5-3.0 in each successive fermenter.

This, and some other similar experiments, showed that by increasing the time of the continuous fermentation from 70 to 110 hours and more, the 
V. L. YAROVENKO AND B. M. NAKHMANOVICH

Table 1. Specific alcohol formation rate in a continuous fermentation of wheat mashes in a series of vessels $\left(\mathrm{ml} \mathrm{g}^{-1} \mathrm{~h}\right)$

\begin{tabular}{cccccc}
\hline $\begin{array}{c}\text { No. of } \\
\text { fermenter } \\
\text { in series }\end{array}$ & 76 & 112 & 137 & 160 & Mean \\
\hline 1 & 1.76 & 2.73 & 1.98 & 2.20 & 2.17 \\
2 & 1.37 & 0.44 & 0.77 & 1.01 & 0.90 \\
3 & 0.35 & 0.14 & 0.07 & 0.56 & 0.28 \\
4 & 0.07 & 0.03 & 0.19 & 0.13 & 0.105 \\
\hline
\end{tabular}

$K$ values for the first fermenter increased in a steady-state process $(D$, mash concentration, temperature, etc. being constant). This fact indicates yeast activation in a prolonged cultivation; the specific rate of alcohol formation may be considered as a function of the reaction rate, $\lambda$, and the activity of the microorganisms, $i, K=f(\lambda, i)^{7}$.

\section{RESULTS AND DISCUSSION}

The fact that the yeast ceased to grow after the third to fifth stages, and that this was followed by a decrease in the yeast cell number, may be due to the effect of the fermentation product formed. According to Ierusalimskii's formula, a relation was established between the specific culture growth rate and the fermentation products ${ }^{3}$

$$
\mu=\frac{M_{0} K_{\mathrm{p}}}{K_{\mathrm{p}}+P}
$$

where $\mu$ is the specific culture growth rate for a given medium completely

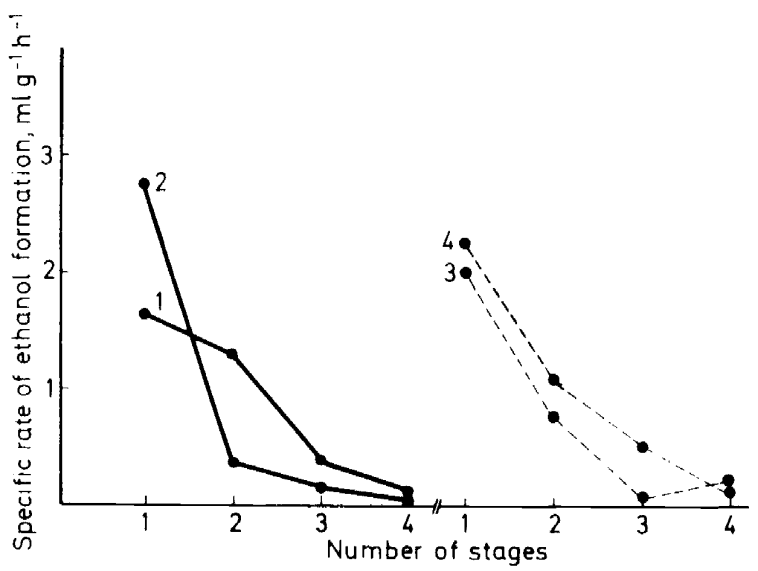

Figure 2. Specific rate of alcohol formation in respective fermentation stages in different experiments. 
free of the growth hindering products, $P$ is the concentration of these products and $K_{\mathrm{p}}$ is a constant, the value of which is equal to the product concentration when the growth rate was reduced to half its original value

$$
\mu=\mu_{0} / 2
$$

Our experimental results show that alcohol considerably decreases the specific growth rate of the yeast, but this influence depends also on the medium composition. In a wheat medium, even 2-3 per cent of alcohol halved the specific growth rate, while in a barley medium the same result was achieved by approximately 5 per cent of alcohol (cf. Figure 3). Thus the $K_{\mathrm{p}}$ values in equation 5 were 0.344 to 0.514 mole per litre for the wheat mashes and about twice as much, 0.858 , for the barley.

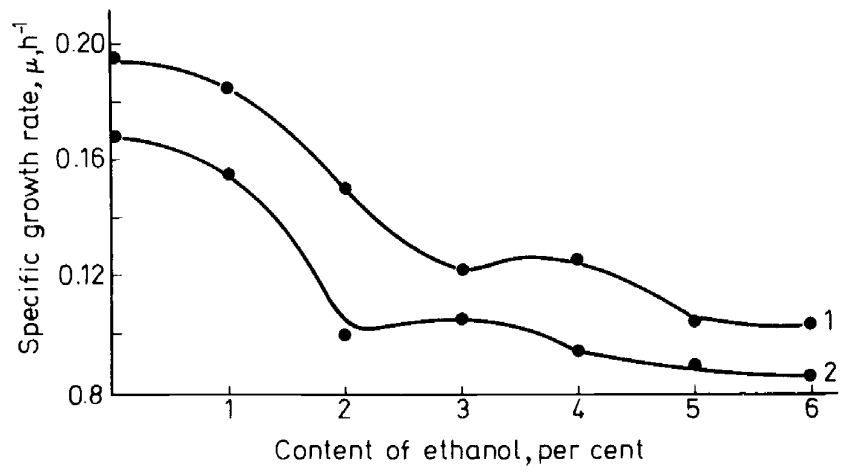

Figure 3. Dependence of specific growth rate on the content of ethanol. 1 -barley medium, 2 - wheat medium.

The $\mu_{\text {max }}$ values for the blank mashes (no alcohol added) were 0.170 and $0.195 \mathrm{~h}^{-\mathrm{pax}}$, respectively. Practically, the specific rate values of the yeast growth in a continuous fermentation of wheat mashes under production or similar conditions were 0.105 to $0.125 \mathrm{~h}^{-1}$; as a rule, they were calculated from the fermented mash assay of the first fermenter in series where the alcohol content was 3 to 4 per cent by volume.

\section{KINETICS OF CONTINUOUS ALCOHOLIC FERMENTATION}

Some aspects of continuous alcoholic fermentation have lately been studied using starchy materials ${ }^{13-15}$, showing that the rate of sugar fermentation under these conditions follows the law of a monomolecular reaction.

According to the Embden-Meyerhof scheme of the alcoholic fermentation mechanism, the process starts with phosphorylation and isomeric conversion of glucose by a number of enzymes into 1,6-fructose-diphosphate, followed by the latter's break-up into two trioses. The primary phosphorylation of glucose is catalysed by the hexokinase enzyme. It is demonstrated in some papers ${ }^{16}$ that the hexokinase reaction is the rate-determining process of the entire fermentation. The dichotomic break-up of the hexose molecule may be 
regarded as a first order reaction and its rate at a given moment is proportional to the concentration of the unreacted substance (fermentable sugars) available. Thus, the sugar fermentation rate may be expressed by

$$
\frac{\mathrm{d} y}{\mathrm{~d} t}=k_{1}(a-y)
$$

where $a$ is the initial concentration of the sugar in the medium: $y$ is the amount of the sugar fermented during time $t,(a-y)$ is the amount of sugar not fermented at time $t$. Sugar concentrations are expressed in grams per $100 \mathrm{ml}$. The fermentable sugar is determined on the glucose basis after complete acid hydrolysis of starch and of the easily hydrolysed carbohydrates without pentoses.

Separation of the variables in equation 6 yields

$$
\frac{\mathrm{d} y}{a-y}=\mathrm{k}_{1} \mathrm{~d} t
$$

and after integration we obtain

$$
k_{1}=\frac{1}{t} \ln \frac{a}{a-y}=\frac{2.303}{t} \log \frac{a}{a-y}
$$

The reaction rate constant, $k_{1}$, shows the part of the substance (sugar) mass unit which reacts in a time unit. The value of the constant undoubtedly depends on the quantity and activity of the yeast, on the concentration of the original mash, and on other conditions of the fermentation: for each of the production cycles studied $k_{1}$ appeared to be practically constant. In various tests (separate production cycles), when fermenting wheat mashes, the reaction rate constants were 0.043 to $0.061 \mathrm{~h}^{-1}$.

The study of the continuous fermentation dynamics and the calculations made show that alcohol formation within the process depends strictly on the amount of sugar fermented. The first fermenter already showed no gap between the amounts of sugar fermented and of the alcohol produced.

The theoretical yield of alcohol using hexoses as substrate can be calculated according to the equation of the alcoholic fermentation reaction

$$
\mathrm{C}_{6} \mathrm{H}_{12} \mathrm{O}_{6}=2 \mathrm{C}_{2} \mathrm{H}_{5} \mathrm{OH}+2 \mathrm{CO}_{2}
$$

where 100 grams of hexoses produce 51.14 grams or $64.79 \mathrm{ml}$ of alcohol the specific weight of the latter being $\mathrm{d}_{4}^{20}=0.78927$.

Sugar losses due to the formation of yeast biomass and of by-products (glycerine, etc.) amount during the fermentation of starchy mashes to approximately 4.0 per cent ${ }^{17}$. The actual alcohol yield from 100 grams of the fermented sugar will then be $62.2 \mathrm{ml}$ as is expressed by the following relation

$$
P=0.622 y
$$

where $P$ is the alcohol per cent by volume.

The calculations of alcohol formation at various stages of continuous fermentation according to the quantity of the fermented sugar are in a good agreement with the analytical results of the actual alcohol content. This is 


\section{KINETICS OF ALCOHOLIC FERMENTATION}

illustrated by experimental results from the laboratory stand (cf. Table 2). Wort samples were taken simultaneously from all fermenters of the battery 72 hours after the battery filling started.

Table 2. Alcohol content in worts at different stages of continuous fermentation obtained by analysis or calculation.

\begin{tabular}{ccccc}
\hline & $\begin{array}{c}\text { Residual } \\
\text { sugar } \\
(a-y)\end{array}$ & $\begin{array}{c}\text { Fermented } \\
\text { sugar, } y\end{array}$ & \multicolumn{2}{c}{$\begin{array}{c}\text { Alcohol content } \\
\%(\mathrm{v} / \mathrm{v})\end{array}$} \\
$\begin{array}{c}\text { Fermenter } \\
\text { No. }\end{array}$ & $\%$ & $\%$ & Analysis & $\begin{array}{c}\text { Calculated } \\
\text { on sugar basis } \\
P=0.622 y\end{array}$ \\
\hline 0 & 11.32 & - & - & - \\
1 & 5.27 & 6.05 & 3.56 & 3.77 \\
2 & 1.76 & 9.56 & 6.07 & 5.95 \\
3 & 1.13 & 10.19 & 6.42 & 6.33 \\
4 & 0.83 & 10.49 & 6.49 & 6.51 \\
5 & 0.78 & 10.54 & 6.56 & 6.56 \\
6 & 0.41 & 10.91 & 6.70 & 6.79 \\
7 & 0.24 & 11.08 & 6.77 & 6.88 \\
8 & 0.18 & 11.14 & 6.84 & 6.93 \\
9 & 0.11 & 11.21 & 6.91 & 6.98 \\
\hline
\end{tabular}

The relations governing the alcohol synthesis in a continuous fermentation are given here on the basis of the 1st order reaction of sugar fermentation (with the rate constant $K_{1}$ ). It is necessary to find $y$ from equation 8 . By conversion

$$
\frac{a}{a-y}=\exp \left(k_{1} t\right)
$$

then

$$
a-y=a \exp \left(-k_{1} t\right) \text { or } y=a\left\{1-\exp \left(-k_{1} t\right)\right\}
$$

Thus, from equation 9 one obtains the quantity of alcohol $(P)$ produced at each time $(t)$ :

$$
P=0.622 a\left\{1-\exp \left(-k_{1} t\right)\right\}
$$

The data obtained according to the above formulas agree well with experimental results. The kinetics curves of alcohol formation in a continuous fermentation are given in Figure 4 (laboratory stand) and Figure 5 (plant production). The curves are plotted versus alcohol concentrations determined by direct analysis using an immersion refractometer (full dots) and calculated according to equation 12 (empty dots).

\section{CONCLUSIONS}

The kinetics of alcohol synthesis was studied in continuous fermentation of starchy media and specific rates of alcohol formation were determined. 


\section{L. YAROVENKO AND B. M. NAKHMANOVICH}

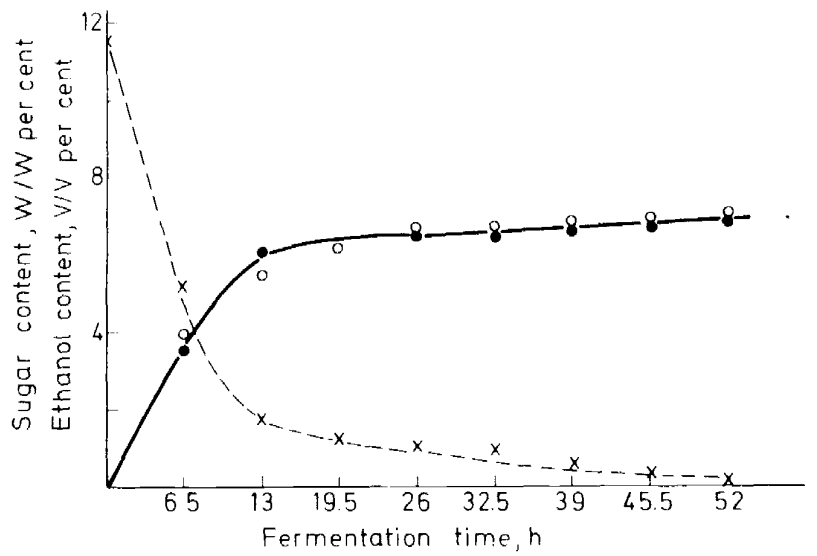

Figure 4. Kinetic curves of alcohol formation in a continuous fermentation in laboratory stand. O--ethanol content calculated from Eq. (12): - ethanol content by analysis: $x-$-sugar content.

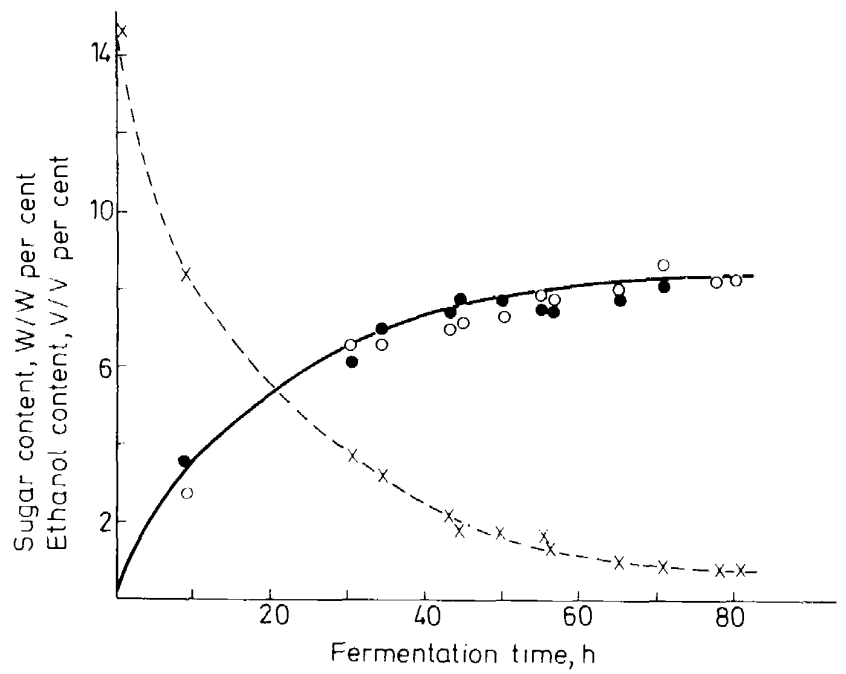

Figure 5. Kinetic curves of alcohol formation in a continuous fermentation in plant production. O-ethanol content calculated from equation 12: - ethanol content by analysis: $\times$ sugar content.

The authors established a relation between the alcohol content in the medium and the specific yeast growth rate. It is shown that sugar fermentation follows the law of a monomolecular reaction.

\section{REFERENCES}

I S. V. Lebedev, Izhrannye rahoty po tekhnologii i khimii brodil nogo i sakharnogo proizvodstva, Pishchepromizdat, Moskva (1958). (In Russian).

2 N. D. Ierusalimskii, Trudy Inst. Mikrobiol. AN SSSR. 6. 20 (1959). (In Russian). 


\section{KINETICS OF ALCOHOLIC FERMENTATION}

${ }^{3}$ N. D. Ierusalimskii, Osnovy fiziologii mikrobov, Izd. AN SSSR, Moskva (196.3). (In Russian).

${ }^{4}$ K. P. Andreev, Mikrobiologiya 28, 264 (1959). (In Russian).

5 I. Monod, Ann. Inst. Pasteur 79, 390 (1950).

${ }^{6}$ I. Holló and L. Nyeste, Nahrung 7, 783 (1956).

${ }^{7} \mathrm{Z}$. Fencl, in Theoretical and methodological basis of continuous culture of microorganisms (1. Málek and Z. Fencl, Eds.), p. 67, Publ. House Czechoslov. Acad. Sci., Prague, (1966).

8 V. L. Yarovenko, Potochnyi metod spirtovogo brozheniya, Pishchepromizdat, Moskva (1958). (In Russian).

9 V. L. Yarovenko, Doctoral thesis, Moscow Technological Institute of Food Industry, Moscow (1963).

10 V. L. Yarovenko, B. M. Nakhmanovich, N. P. Shcheblykin and V. V. Senkevich, Nepreryvnoe brozhenie $v$ aceoto-butilovom proizvodstve, Kabard-Balkar. Knizhn. izd., Nal'chik (1963). (In Russian).

11 V. L. Yarovenko, Spirt. Promyshl. 21, (3), 15 (1955). (In Russian).

12 D. N. Klimovskii and V. N. Stabnik ov, Tekhnologiya spirtovogo proivodstva, Pishchepromizdat, Moskva (1958). (In Russian).

1.3 V. L. Yarovenko and B. M. Nakhmanovich, Izv. Vyssh. Ucheb. Zaved. Pishchev. Tekhnol.. 1, 82 (1970). (In Russian).

14 V. L. Yarovenko and B. M. Nakhmanovich, Ferment. Spirt. Promyshl. 2, 47 (1970). (In Russian).

15 V. L. Yarovenko, B. M. Nakhmanovich and L. T. Ermakova, Izv. Vyssh. Ucheb. Zaved., Pishchev. Tekhnol., 3, 93 (1970). (In Russian).

16 S. A. Konovalov, Biokhimiya brodil'nylh proizvodstv, Pishchepromizdat, Moskva (1967). (In Russian).

17 D. N. Klimovskii, V. A. Smirnov and V. N. Stabnikov, Tekhnologiya spirta, Pishchepromizdat, Moskva (1967). (In Russian). 